\title{
Improving health care by embracing Systems Theory
}

\author{
Brett R. Anderson, MD, MBA, MS/POR
}

\author{
From the Division of Pediatric Cardiology, NewYork-Presbyterian/Morgan Stanley Children's Hospital, \\ Columbia University Medical Center, New York, NY. \\ Supported by the National Center for Advancing Translational Sciences (grant No. KL2 TR000081). \\ Disclosures: Author has nothing to disclose with regard to commercial support. \\ Received for publication March 15, 2016; accepted for publication March 16, 2016; available ahead of print April \\ 23, 2016. \\ Address for reprints: Brett R. Anderson, MD, MBA, MS/POR, Division of Pediatric Cardiology, NewYork- \\ Presbyterian/Morgan Stanley Children's Hospital, 3959 Broadway, 2 N, New York, NY 10032-3784 \\ (E-mail: bra2113@cumc.columbia.edu). \\ J Thorac Cardiovasc Surg 2016;152:593-4 \\ $0022-5223 / \$ 36.00$ \\ Copyright $(2016$ by The American Association for Thoracic Surgery \\ http://dx.doi.org/10.1016/j.jtcvs.2016.03.029
}

The development of Systems Theory is largely accredited to Austrian biologist Karl Ludwig von Bertalanffy. Beginning in the 1920s, von Bertalanffy lectured on the limitations of the Newtonian concepts of closed systems and linear cause and effect. In his seminal work in 1969, von Bertalanffy described what has since become known as General Systems Theory, the concept that systems cannot be reduced to a series of parts functioning in isolation, but that, in order to understand a system as a whole, one must understand the interrelations between its parts. ${ }^{1}$

During the past half-century, Systems Theory has spread across disciplines, from psychology to engineering. By the 1980s and 1990s, management science began to apply Systems Theory broadly. ${ }^{2}$ Application of this theory rests on the assumption that most individuals strive to do good work, but that they are acted upon by diverse influences. It further relies on the premise that functional and efficient systems not only account for, but also embrace, these influences. Causal analysis based on Systems Theory asserts that, when errors occur, one ought not focus solely on individual failings, but on the surroundings that allowed such events to transpire. It further asserts that outcomes can be influenced by smart interventions developed after studying common patterns and behaviors across time.

The underlying principles of Systems Theory should seem largely intuitive to health care professionals. Although many of us spend considerable time siloed, focusing on the functionings of individual organs, our jobs necessitate that we think about how each intricate organ system influences, and is influenced by, its environment. We think about how renal function is influenced by the squeeze of the cardiac muscles, and simultaneously by the medications a patient is taking, the sepsis his or her body is fighting, and the preexisting renal disease with which he or she came. A transplanted organ is influenced not only by immunosuppressant medications and other medical conditions, but also by a patient's social environment, support network,

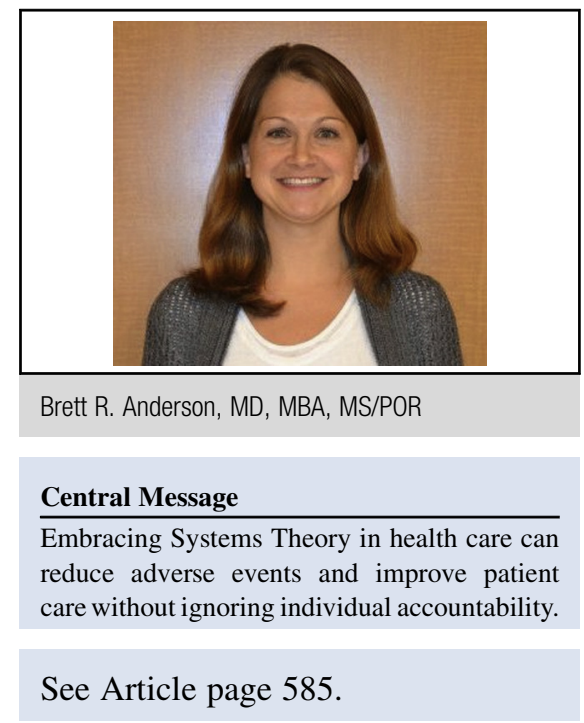

and developmental stage. There is no debate, for example, that the risk of transplant rejection is higher among teenagers than among young children who are not yet trying to assert their independence.

In the 1999 landmark report to Congress, ${ }^{3}$ To Err Is Human, The Institute of Medicine advocated that quality improvement attention be turned on the health care system as a whole. That was more than 15 years ago. Why, then, has health care been so slow to adopt Systems Theory? Some have argued that health care is simply really, really complex, and that complexity is "inconvenient" for managers. ${ }^{2}$ But health care is hardly the most complex of industries, so this inadequately explains the relative dearth of progress. ${ }^{4}$

The most compelling explanation I have encountered relates to medicine's culture. Until recently, medical education and socialization have emphasized the responsibility of the individual above all else. ${ }^{5}$ Dr Nancy Leveson and Dr Sidney Dekker, coauthors of When a Checklist Is not Enough, ${ }^{6}$ engaged with Dr Philip Levitt, a retired neurosurgeon and former hospital chief of staff, regarding the application of Systems Theory in health care. $^{7-9}$ Levitt argued that $2 \%$ to $3 \%$ of health care professionals are simply bad seeds, and that the key to quality improvement lies in removing these individuals from the field. He had strong literature to support his claims (although some might question the risk adjustment methodologies employed). But Levitt failed to understand that individual accountability and Systems Theory are not mutually exclusive. ${ }^{8,9}$ One can hold individuals responsible where appropriate while simultaneously looking holistically 
at the system to identify weakness that allow for, or even enable, adverse events.

It is convenient to think about management as a linear process, with each adverse event having an identifiable, antecedent cause. But how do we effect sustainable change based on this sort of simplistic view? Raman and colleagues ${ }^{6}$ provide an example of 4 separate adverse events stemming from inadequate training of 4 different nurses. Should the managers in these cases have disciplined the nurses for their lack of knowledge when the nurses were forced to cover procedures for which they were not trained? Were the managers culpable for having placed ill-prepared nurses in situations that needed to be staffed, when no one else was available? Perhaps the physicians, or their administrative assistants, should be required to check nursing availability before booking procedures? Focusing too intently on the specifics of individual cases often misplaces blame and leaves important questions unanswered. Applying Systems Theory, in contrast, lumps adverse events together across types and allows us to detect patterns and system failures. While we should not ignore individual accountability, as an industry we need to become more self-reflective and devote our efforts to designing smarter systems that protect against inevitable fallibility.

\section{References}

1. von Bertalanffy L. General system theory; foundations, development, applications. New York: G. Braziller; 1969.

2. Straub R. Why managers haven't embraced complexity. Harv Bus Rev. May 6, 2013. Available at: https://hbr.org/2013/05/why-managers-havent-embraced-c. Accessed March 28, 2016.

3. Kohn LT, Corrigan JM, Donaldson MS. To err is human: building a safer health system. Washington: National Academies Press; 2000.

4. More than 1000 preventable deaths a day is too many: the need to improve patient safety. Available at: http://www.help.senate.gov/hearings/hearing/?id=478e8a355056-a032-52f8-a65f8bd0e5ef. Accessed March 28, 2016

5. Edmondson AC. The kinds of teams health care needs. Harv Bus Rev. December 16, 2015. Available at: https://hbr.org/2015/12/the-kinds-of-teams-health-careneeds. Accessed March 28, 2016.

6. Raman J, Samost L, Leveson NG, Dobrilovic N, Oldham M, Dekker SW, et al. When a checklist is not enough: how to improve them and what else is needed. J Thorac Cardiovasc Surg. 2016;152:585-92.

7. Dekker SW, Leveson NG. The bad apple theory won't work: response to 'Challenging the systems approach: why adverse event rates are not improving' by Dr Levitt. BMJ Qual Saf. 2014;23:1050-1.

8. Levitt P. Challenging the systems approach: why adverse event rates are not improving. BMJ Qual Saf. 2014;23:1051-2.

9. Levitt P. When medical errors kill. Los Angeles: Los Angeles Times; March 15, 2014. 